\title{
Zum Andenken an Henry E. Sigerist (1891-1957)*
}

Gestatten Sie mir ein kurzes Wort der Erinnerung an Prof. Dr. med. Henry E. Sigerist, Ehrenmitglied unserer Gesellschaft, der nach längerem Leiden am 17. März dieses Jahres in die ewige Heimat eingegangen ist.

Henry Sigerist, zu Paris am 7. April 1891 geboren, von schaffhauserischer Abkunft, war vor 26 Jahren Gründungsmitglied unserer am 4. Dezember 1921 ins Leben gerufenen Gesellschaft. Ihm und den Veteranen unserer Gesellschaft, einem Arnold C. Klebs, André Guisan, W. von Rodt, Gustav Senn, Jean Strohl, R. von Fellenberg, unter denen nur noch der Letztgenannte sich des Lebens erfreut, vor allem aber Sigerists temperamentvoller Initiative und beredter Überzeugungskraft verdanken wir die Gründung unserer Gesellschaft, als deren erster Sekretär er tatkräftig amtete. Es war deshalb ein Akt wohlverdienter Ehrung durch unsere Gesellschaft, daß wir vor sechs Jahren, bei Anlaß seines 60. Geburtstages, den Gesnerus in einer kleinen Festschrift Henry Sigerist widmeten.

Es ist hier nicht der Ort, den glänzenden Aufstieg Sigerists von der Privatdozentur für Geschichte der Medizin an der Zürcher Universität (1921-1925) zum Leiter des Sudhoff-Institutes für Geschichte der Medizin in Leipzig (1925 bis 1932) und schließlich zum Direktor des «Institute for the History of Medicine» an der Johns Hopkins University in Baltimore (1932-1947) näher darzustellen.

Jedermann weiß - und das ist auch in allen Nachrufen auf Henry Sigerist zum Ausdruck gekommen -: Johns Hopkins wurde unter Sigerist zum Weltzentrum für Geschichte der Medizin.

Dies sagen zu können, setzt eine bedeutende Persönlichkeit und ein fast unglaubliches Wissen, setzt hervorragende Sprachbegabung, setzt aber auch einen unerschütterlich optimistischen Willen voraus, sich für eine Wissenschaft mit allen Kräften des Geistes und der Seele einzusetzen, deren Bedeutung und Wert damals noch durchaus umstritten waren und die auch heute noch, trotz des universalen Wirkens Sigerists, immer wieder um ihre Anerkennung kämpfen muß. - Kommen nun noch, wie es bei Sigerist der Fall war, ein ausgesprochenes Organisationstalent und eine unerhört anschauliche, ja faszinierende Beredsamkeit, eine seltene Bereitschaft zur Zusammenarbeit und eine menschliche Liebenswürdigkeit hinzu, so versteht man einigermaßen, wie es zu dieser großen weltweiten Wirksamkeit und wissenschaftlichen Leistung kommen konnte.

Auf Baltimore folgte Pura (1947-1957), folgte die gesundheitlich bedingte Rückkehr in die Heimat. Nicht zur Muße, sondern mit dem klaren Willen, die letzte Stufe seines Lebens großen wissenschaftlich-literarischen Plänen zu wid-

* Erinnerungsworte, gesprochen in der Mitgliederversammlung der Schweizerischen Gesellschaft für Geschichte der Medizin und der Naturwissenschaften, Neuchâtel, am 22. September 1957. 
men. Sie sind Torso geblieben, wie seine auf sieben Bände geplante History of Medicine, von der Sigerist nur noch den ersten Band zu vollenden vermochte. Schon dieser eine Band läßt erkennen, wie weit gespannt Sigerist den Begriff der Geschichte der Medizin gefaßt haben wollte: Über rein fachtechnische oder biographische, aber auch über politische, kulturhistorische und künstlerische Aspekte hinaus sind es vor allem soziologische und soziale Gesichtspunkte, welche ihn die Geschichte der Medizin neu erleben und gestalten ließen.

Man darf ohne Übertreibung sagen, daß Sigerist die Grundlagen der Geschichte der Medizin neu gefaßt und ihren Wirkungsbereich und ihre Bedeutung im Gesamtrahmen der historischen Wissenschaften neu bestimmt hat.

Wir erleben heute im Zeitalter der Kernphysik und der Atomzertrümmerung in fast allen Ländern - am wenigsten deutlich vielleicht in der Schweiz, wenn wir die Verhältnisse etwa mit Belgien oder Holland vergleichen - einen gewaltigen Aufschwung der Geschichte der exakten Naturwissenschaften, für welche in den genannten und in andern Ländern eigene Lehrstühle errichtet worden sind. Ist dabei auch das allgemeine Interesse an Kernphysik und Atomtechnik mit im Spiel, so ist dieser Aufschwung ohne die von Sigerist geschaffenen Voraussetzungen kaum zu denken. Seien wir uns dieser erfreulichen Tatsache bewußt, aber versäumen wir auch nicht den Augenblick, für die Entwicklung der Medizingeschichte aufs wärmste einzustehen, die es wahrhaft verdient, daß ihre Annalen nicht der Vergessenheit anheimfallen.

Die Schweizerische Gesellschaft für Geschichte der Medizin und der Naturwissenschaften gedenkt mit großer Dankbarkeit der vielen Anregungen und Dienste, welche uns Henry Sigerist im Laufe vieler Jahre geleistet hat. Nicht zuletzt verdankt ihm der Redaktor des Gesnerus vielfältige Aufmunterung in Situationen, in denen die Herausgabe unserer Vierteljahrsschrift besondere Schwierigkeiten bot.

Das Andenken an Henry Sigerist wird unter uns ein dauerndes sein, solange überhaupt Medizingeschichte und Geschichte der Naturwissenschaften in unserm Land Interesse finden werden und als ein vaterländisches und doch weltweites nobile officium lebendig, das heißt aber, mit Begeisterung gepflegt wird.

H. Fischer 